\title{
In vitro Antifungal Effect of Mangrove extracts on Fusarium verticillioides Isolates
}

\author{
I. G. MARTÍNEZ-ÁLVAREZ, KARLA Y. LEYVA-MADRIGAL, I. E. MALDONADO-MENDOZA*, MARÍA E. JARAMILLO-FLORES ${ }^{1}$ \\ AND H. A. GONZÁLEZ-OCAMPO \\ Instituto Politécnico Nacional, Centro Interdisciplinario de Investigación para el Desarrollo Integral Regional (CIIDIR)-Unidad \\ Sinaloa. Boulevard Juan de Dios Bátiz Paredes \# 250, Col. San Joachin, 81101, Guasave, Sinaloa, ${ }^{1}$ Instituto Politécnico \\ Nacional, Escuela Nacional de Ciencias Biológicas, Unidad Profesional Lázaro Cárdenas, Ampliación del Carpio y Plan de Ayala \\ s/n, Col. Santo Tomas C.P. 11340 Del., Miguel Hidalgo, México
}

\section{Martínez-Álvarez et al.: Antifungal effect of Mangrove extracts}

\begin{abstract}
The present study was conducted to identify the antifungal activity of phenolic compounds extracted from the mangrove, Rhizophora mangle against the Fusarium verticillioides isolates DA42, F64 and PO3. The total phenolic content was calculated using the Folin-Ciocalteu method. The in vitro inhibition test was performed according to the poisoned food technique. Stem extracts had the highest total phenolic content $(9.5 \mathrm{mg}$ gallic acid equivalents/g dry biomass) and displayed major inhibition percentages against all Fusarium verticillioides isolates. Furthermore, the concentration of the stem extract required to inhibit the three fungal isolates by $50 \%$, is 2 to 3 times greater on average than that required for leaf and root extracts. This study demonstrated the inhibitory activity of ethanol extracts of Rhizophora mangle roots, stems and leaves against different isolates of Fusarium verticillioides.
\end{abstract}

Key words: Antifungal effect, extracts, phenolic compounds, Fusarium verticillioides, fungal growth inhibition, Rhizophora mangle

Restrictions on the use of synthetic fungicides have been implemented in the last decade, due to their negative impact on the environment and the rapid emergence of resistant fungal isolates. This has driven researchers to find alternative fungicidal compounds ${ }^{[1]}$. Mangroves are one source of these compounds. These woody plants are found in tropical and subtropical intertidal regions, and are able to grow under extreme local environmental conditions including high salinity, extreme tides, strong winds and high temperatures, as well as muddy, anaerobic soils ${ }^{[2,3]}$. These stress conditions promote the production of antioxidants such as phenols, which are used to counteract the effect of reactive oxygen species ${ }^{[4,5]}$. Importantly, several studies have already reported the antifungal activity of mangrove phenolic extracts ${ }^{[6-8]}$. In particular, mangrove species of the Rhizophoraceae family have a high concentration and diversity of phenols ${ }^{[4,5,9,10]}$, which are reported to be effective against different fungal species $^{[11,12]}$.

This is an open access article distributed under the terms of the Creative Commons Attribution-NonCommercial-ShareAlike 3.0 License, which allows others to remix, tweak, and build upon the work non-commercially, as long as the author is credited and the new creations are licensed under the identical terms

Accepted 18 December 2018

Revised 07 May 2018

Received 21 April 2017

Indian J Pharm Sci 2019;81(1):181-187 
The study and use of phenolic compounds as a strategy for controlling pathogenic fungi has increased in recent years ${ }^{[13,14]}$. Several pathogenic species are found within the fungal genus Fusarium ${ }^{[15]}$, this includes Fusarium verticillioides, the widely distributed causative agent of stalk, ear and root rot in maize ${ }^{[16,17]}$. Aside from decreasing grain yield and quality ${ }^{[18-20]}$, this fungus produces a variety of mycotoxins that contaminate maize grain, thereby threatening animal and human health ${ }^{[15]}$.

Chemical control of this fungus has been inadequate, making it necessary to find effective alternatives to monitor the effects of this pathogen. As stated above, previous research has examined the antifungal properties of mangrove phenolic compounds, although no comprehensive studies have been performed on the antifungal activity of $R$. mangle phenolic extracts against pathogenic fungi $F$. verticillioides. The aim of this work was therefore to investigate the antifungal activity of ethanol extracts from $R$. mangle organs against $F$. verticillioides.

Mangrove leaves, stems and roots were collected from Terminos Lagoon (Campeche, Mexico; 18²9'33.42" N, 91 $\left.{ }^{\circ} 47^{\prime} 26.32^{\prime \prime} \mathrm{W}\right)$ in August, 2011. The samples were collected and kept in sealed amber bottles to protect them from sunlight. Subsequently, the samples were dehydrated in an oven (Riossa E-47) at $40^{\circ}$ until they reached a constant weight. The dehydrated samples were then ground into a fine powder.

Aliquots (6.25 g) of dehydrated and ground mangrove leaves, stems and roots were extracted with $250 \mathrm{ml}$ of ethanol-water $(80: 20 \mathrm{v} / \mathrm{v})$. Each aliquot was protected from light with a cover and shaken in a multiple position stirrer (Corning, Cat. 440826; Corning, NY, USA) at $800 \mathrm{rpm}$ for $30 \mathrm{~min}$. The resulting extracts were filtered through Whatman No. 1 filter paper and the ethanol was completely evaporated at $40^{\circ}$ using a rotary evaporator (Buchi R-210/R-215; Flawil, Switzerland). The volume of each extract was adjusted to $50 \mathrm{ml}$ of ethanol-water $(80: 20 \mathrm{v} / \mathrm{v})$ solution and stored in amber vials at $4^{\circ}$ until use.

The total phenolic content (TPC) from $R$. mangle tissues was determined using the Folin-Ciocalteu method ${ }^{[21]}$. An aliquot of $100 \mu \mathrm{l}$ of each extract was mixed with $750 \mu 1$ of Folin-Ciocalteu reagent (1:10 dilution in distilled water); $750 \mu \mathrm{l}$ of $\mathrm{Na}_{2} \mathrm{CO}_{3}$ solution $(60 \mathrm{~g} / \mathrm{l})$ was then added 5 min later. The mix was incubated for $90 \mathrm{~min}$ and the absorbance was subsequently read in a spectrophotometer (Multiskan GO Microplate reader,
Thermo Fisher Scientific; Waltham, MA, USA) at $750 \mathrm{~nm}^{[22]}$. TPC from $R$. mangle extracts was recorded as gallic acid equivalents (GAE) per gram of dry biomass (DM).

Three fungal isolates of $F$. verticillioides (PO3, DA42 and F64) were used as test organisms. These isolates are part of a Fusarium collection isolated from maize seeds and roots, belonging to the Laboratory of Molecular Ecology of the Rhizosphere at CIIDIRSinaloa (Mexico). Fungal isolates were grown on potato dextrose agar (PDA, BDBioxon, Edo. de Mexico) for five days at $25^{\circ}$.

Mycelial growth inhibition of $F$ verticillioides was tested in vitro according to the poisoned food technique ${ }^{[22]}$. A dose-response test was performed for each phenolic extract by adding between 0.5-3 ml of extract to a $9 \mathrm{~mm}$ Petri dish containing $20 \mathrm{ml}$ of PDA. Final concentrations of phenolic extracts per milliliter of PDA for each test are reported in Table 1. Petri dishes were inoculated in the centre with a mycelial plug (5 $\mathrm{mm}$ in diameter) from a 5 -d old $F$. verticillioides culture. Growth inhibition percentage of $F$. verticillioides was calculated according to the following Eqn., inhibition $\%=[(\mathrm{C}-\mathrm{T}) / \mathrm{C}] \times 100$, where $\mathrm{C}$ is the mycelium diameter of the control and $\mathrm{T}$ is the mycelium diameter of the treatments ${ }^{[22]}$. Petri dishes containing PDA with the equivalent ethanolwater $(80: 20 \mathrm{v} / \mathrm{v})$ volume were inoculated with a F. verticillioides mycelial plug and used as controls (C) per each concentration of extract used. To determine the lethal concentration of $F$. verticillioides, a doseresponse curve for benomyl (Benoma-T, Velsimex Company, Mexico, D.F.) was performed using PDA plates with $0.5,1.25,2.5$ and $5 \mathrm{mg} / \mathrm{ml}$. PDA plates without benomyl were used as a control. Incubation was carried out in the dark at $35^{\circ}$ for seven days. Each treatment was performed in triplicate.

Data from the growth inhibition test of each phenolic extract were subjected to analysis of variance (ANOVA), and Tukey's test was used for post-hoc comparison of means $(p \leq 0.05)$. The inhibition percentages were arcsine-transformed before ANOVA. A two-way ANOVA model was used to determine the phenolic concentration of each extract and the Fusarium isolate effects on growth inhibition. Individual differences among phenolic concentrations and Fusarium isolates were determined by Tukey's test. The mean inhibition percentages of each treatment were entered into a weighted linear regression model to account for 
the differences in phenolic concentrations between extracts. This model was used to calculate the phenolic concentration needed to inhibit fungal growth by $50 \%$. All statistical tests were performed using the SAS 9.0 software (SAS Institute, Inc.; Cary, NC, USA).

The TPC of $R$. mangle leaf, stem and root extracts ranged from 0.777 to $9.5 \mathrm{mg} \mathrm{GAE} / \mathrm{g} \mathrm{DM}$, with significant differences between them. Stem extracts displayed the highest level of TPC (9.5 mg GAE/g $\mathrm{DM}$ ), followed by root (2.56 $\mathrm{mg}$ GAE/g DM) and leaf (0.777 mg GAE/g DM) extracts (fig. 1A). The synthetic fungicide benomyl was used as a control for mycelial growth inhibition and used as a reference. A doseresponse curve was performed to determine the lethal dose of this chemical on the different $F$. verticillioides isolates (fig. 1B). A differential response among the various isolates at lowerbenomyl concentrations $(0.5$ and $1.25 \mathrm{mg} / \mathrm{ml}$ ) was observed, whereas all isolates showed $100 \%$ inhibition in response to $2.5 \mathrm{mg} / \mathrm{ml}$ benomyl. The latter concentration was therefore selected for use in the growth inhibition test. All mangrove extracts were capable of inhibiting mycelial growth of the different $F$. verticillioides isolates (Table 1 ). In every

A

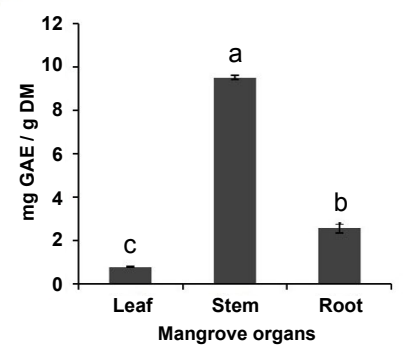

B
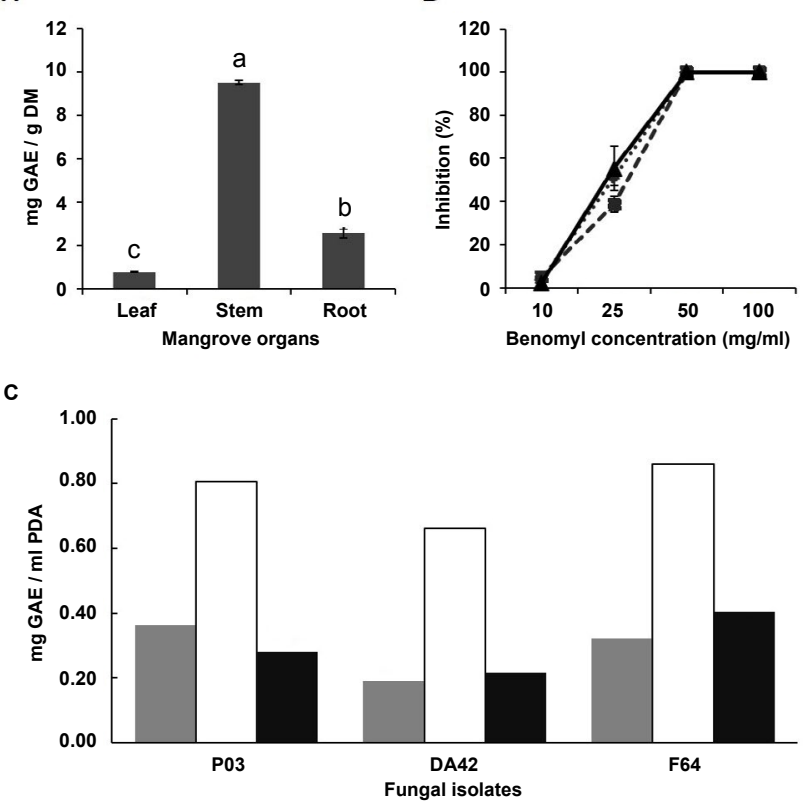

Fig. 1: Total phenolic content of $R$. mangle and effects on $F$. verticillioides mycelial growth, compared to a fungicide A) Total phenolic content (TPC) from different $R$. mangle organs (leaf, stem and root). Different letters are significantly different at a probability level of $\mathbf{0 . 0 5}$, according to Tukey's test. B) Benomyl dose-response curve for different $\boldsymbol{F}$. verticillioides isolates, ...\$... P03, - - Da42, - $\Delta-$ F64. C) Phenolic concentrations of mangrove leaf (grey bars), stem (white bars) and root (black bars) extracts required to inhibit different F. verticillioides isolates by $50 \%$, as calculated from the obtained linear regression formulas case, the inhibition percentage increased along with phenolic concentration.

Results from the two-way ANOVA are reported in Table 2. Both phenolic concentration and the Fusarium isolate (as well as the interaction between these two factors) had significant effects on the growth inhibition percent. The three mangrove extracts were more efficient at inhibiting DA42 than P03 or F64 (Table 3), which could be due to genetic differences between the fungal isolates. Comparing mangrove extracts in the inhibition test was difficult due to differences in their phenolic concentrations. Inhibition percentages from each mangrove extract/fungal isolate combination were therefore adjusted to a linear regression model, and the phenolic concentration required to inhibit fungal growth by $50 \%$ was calculated using the estimated regression formula for each combination (fig. 1). There was a significant relationship between inhibition percent and phenolic concentration for all combinations, revealing high correlation coefficients $\left(\mathrm{R}^{2}\right)$ that ranged from 0.9125 (isolate F64, root extract) to 0.9822 (isolate DA42, leaf extract).

As stated above, the stem extract sample displayed the highest TPC value (9.5 mg GAE/g DM) and resulted in major inhibition percent in all $F$. verticillioides isolates (Table 1). However, the required concentration of this extract to inhibit the three fungal isolates by $50 \%$ is two to three times greater on average than that required for leaf and root extracts (fig. 1C). In the present study, ethanol extracts from different red mangrove (R. mangle) organs were obtained, and their antifungal activity was evaluated against three $F$. verticillioides isolates from maize roots.

TPC varied greatly among the different mangrove organs. The highest phenol content was found in the stem extract, followed by root and leaf extracts. The same pattern was previously observed in other mangrove species belonging to the Rhizophoraceae family, including $R$. mucronata, Bruguiera gymnorrhiza, Ceriops decandra ${ }^{[4,9]}$ and $R$. stylosa ${ }^{[5]}$. Although the ethanol extracts from $R$. mangle tested in this study were able to inhibit $F$. verticillioides growth, the response was variable and dependent on the type of extract (root, stem or leaf), its concentration, and the particular isolate (F64, DA42 or P03). Previous reports have demonstrated that phenolic extracts from several mangrove species exhibit antifungal activity against different fungal species ${ }^{[6,7]}$. It is believed that phenolic compounds can diffuse through the fungal membrane 

FUSARIUM VERTICILLIOIDES ISOLATES

\begin{tabular}{|c|c|c|c|c|}
\hline \multirow{2}{*}{$\begin{array}{l}\mathrm{EV} \\
(\mathrm{ml})\end{array}$} & \multirow{2}{*}{$\begin{array}{c}\mathrm{EC} \\
\text { (mg GAE/mI PDA) }\end{array}$} & \multicolumn{3}{|c|}{ Growth inhibition percent } \\
\hline & & P03 & DA42 & F64 \\
\hline \multicolumn{5}{|c|}{ Leaf extract } \\
\hline 0.5 & 0.056 & $0.00 \pm 0.00^{e}$ & $0.00 \pm 0.00^{e}$ & $0.00 \pm 0.00^{d}$ \\
\hline 1 & 0.113 & $8.33 \pm 3.61^{d}$ & $8.00 \pm 0.00^{d}$ & $6.25 \pm 6.25^{c d}$ \\
\hline 1.5 & 0.170 & $10.42 \pm 3.61^{\mathrm{cd}}$ & $37.30 \pm 9.23^{c}$ & $8.33 \pm 3.60^{\mathrm{bc}}$ \\
\hline 2 & 0.227 & $18.75 \pm 0.00^{\mathrm{bc}}$ & $60.00 \pm 0.00^{\mathrm{bc}}$ & $22.91 \pm 3.60^{\mathrm{ab}}$ \\
\hline 2.5 & 0.283 & $29.17 \pm 7.22^{\mathrm{ab}}$ & $72.00 \pm 6.92^{b}$ & $39.58 \pm 3.60^{\mathrm{a}}$ \\
\hline 3 & 0.340 & $41.67 \pm 3.61^{\mathrm{a}}$ & $94.66 \pm 4.61^{\mathrm{a}}$ & $45.83 \pm 3.60^{\mathrm{a}}$ \\
\hline \multicolumn{5}{|c|}{ Stem extract } \\
\hline 0.5 & 0.237 & $8.33 \pm 3.61^{e}$ & $0.00 \pm 0.00^{f}$ & $10.41 \pm 3.60^{\mathrm{e}}$ \\
\hline 1 & 0.475 & $20.83 \pm 7.22^{\mathrm{d}}$ & $36.25 \pm 2.31^{\mathrm{e}}$ & $18.75 \pm 0.00^{d}$ \\
\hline 1.5 & 0.712 & $37.50 \pm 0.00^{c}$ & $51.25 \pm 2.31^{\mathrm{d}}$ & $33.33 \pm 3.60^{c}$ \\
\hline 2 & 0.950 & $45.83 \pm 3.61^{c}$ & $75.00 \pm 0.00^{c}$ & $41.66 \pm 3.60^{c}$ \\
\hline 2.5 & 1.187 & $68.75 \pm 0.00^{\mathrm{b}}$ & $91.25 \pm 2.31^{\mathrm{b}}$ & $60.41 \pm 3.60^{\mathrm{b}}$ \\
\hline 3 & 1.425 & $91.67 \pm 3.61^{\mathrm{a}}$ & $100.0 \pm 0.00^{\mathrm{a}}$ & $85.41 \pm 3.60^{\mathrm{a}}$ \\
\hline \multicolumn{5}{|c|}{ Root extract } \\
\hline 0.5 & 0.064 & $4.17 \pm 3.61^{\mathrm{e}}$ & $20.00 \pm 0.00^{\mathrm{e}}$ & $0.00 \pm 0.00^{e}$ \\
\hline 1 & 0.128 & $16.67 \pm 3.61^{\mathrm{d}}$ & $20.00 \pm 0.00^{e}$ & $10.41 \pm 3.60^{d}$ \\
\hline 1.5 & 0.192 & $25.00 \pm 0.00^{c d}$ & $37.33 \pm 4.61^{\mathrm{d}}$ & $16.66 \pm 3.60^{c}$ \\
\hline 2 & 0.256 & $37.50 \pm 0.00^{\mathrm{bc}}$ & $52.00 \pm 6.92^{c}$ & $18.75 \pm 0.00^{\mathrm{bc}}$ \\
\hline 2.5 & 0.316 & $43.75 \pm 0.00^{\mathrm{b}}$ & $69.33 \pm 2.31^{\mathrm{b}}$ & $25.00 \pm 0.00^{b}$ \\
\hline 3 & 0.384 & $66.67 \pm 3.61^{\mathrm{a}}$ & $80.00 \pm 0.00^{a}$ & $43.75 \pm 0.00^{\mathrm{a}}$ \\
\hline
\end{tabular}

EV: extract volume added to PDA and adjusted to $20 \mathrm{ml}$, EC: extract concentration in PDA plates. Means with different letters are significantly different at a probability level of 0.05 according to Tukey's test. The reported means of growth inhibition percentage were arcsine transformed $(\delta(\mathrm{x} \% / 100)+0.5)$ to normalize the data and proceed with the ANOVA. No significant differences were recorded in mycelial growth of $F$. verticillioides cultivated in Petri dishes containing PDA with equivalent ethanol-water $(80: 20 \mathrm{v} / \mathrm{v})$, per each concentration of extract

TABLE 2: TWO-WAY ANOVA OF PERCENT GROWTH INHIBITION AS THE DEPENDANT VARIABLE AND PHENOLIC CONCENTRATIONS AND FUSARIUM ISOLATES AS FACTORS

\begin{tabular}{|c|c|c|c|c|c|c|c|c|c|c|c|c|}
\hline \multirow{2}{*}{ Source } & \multicolumn{4}{|c|}{ Leaf extract } & \multicolumn{4}{|c|}{ Stem extract } & \multicolumn{4}{|c|}{ Root extract } \\
\hline & d.f & MS & $\mathbf{F}$ & $\mathrm{p}$ & d.f. & MS & $\mathrm{F}$ & $p$ & d.f. & MS & $\mathrm{F}$ & $p$ \\
\hline \multicolumn{13}{|l|}{ GIP } \\
\hline PC & 5 & 5.215 & 188.46 & $<0.0001$ & 5 & 5.578 & 626.31 & $<0.0001$ & 5 & 2.892 & 263.91 & $<0.0001$ \\
\hline $\mathrm{Fi}$ & 2 & 1.154 & 104.3 & $<0.0001$ & 2 & 1.147 & 322.16 & $<0.0001$ & 2 & 1.043 & 237.93 & $<0.0001$ \\
\hline $\mathrm{PCXFi}$ & 10 & 0.665 & 12.03 & $<0.0001$ & 10 & 0.091 & 5.16 & $<0.0001$ & 10 & 0.141 & 6.46 & $<0.0001$ \\
\hline
\end{tabular}

The reported means of growth inhibition percentage were arcsine transformed $(J(x \% / 100)+0.5)$ to normalize the data and proceed with the ANOVA. GIP: growth inhibition percentage, PC: phenolic concentration, Fi: fungal isolate, d.f.: degrees of freedom; MS: mean square; $\mathrm{F}$ : $\mathrm{F}$ ratio; $\mathrm{p}$ : probability

TABLE 3: EFFECT OF FUSARIUM ISOLATE GROWTH INHIBITION PERCENTAGES VERSUS PHENOLIC EXTRACTS FROM DIFFERENT RHIZOPHORA MANGLE TISSUES

\begin{tabular}{lccc}
\hline \multirow{2}{*}{ Isolate } & \multicolumn{3}{c}{ Growth inhibition percentage } \\
\cline { 2 - 4 } & Leaf & Stem & Root \\
\hline P03 & $18.05 \pm 14.67^{\mathrm{b}}$ & $45.48 \pm 29.06^{\mathrm{b}}$ & $32.29 \pm 20.81^{\mathrm{b}}$ \\
DA42 & $45.33 \pm 35.08^{\mathrm{a}}$ & $63.78 \pm 28.22^{\mathrm{a}}$ & $46.44 \pm 23.80^{\mathrm{a}}$ \\
F64 & $20.13 \pm 17.48^{\mathrm{b}}$ & $41.66 \pm 26.16^{\mathrm{c}}$ & $19.09 \pm 13.97^{\mathrm{c}}$ \\
\hline
\end{tabular}

Means with different letters in the same column are significantly different according to Tukey's test. The reported means of growth inhibition percentages were arcsine transformed $(J(\mathrm{x} \% / 100)+0.5)$ to normalize the data and proceed with the ANOVA and penetrate into the cell, where they interfere with essential metabolic pathways (such as the synthesis of ergosterol, glucan and chitin), leading to the disruption of membrane integrity, fluidity and loss of intracellular content ${ }^{[23]}$.

The phenolic profile depends on a number of factors including the plant genotype, and the organ, tissue or phenological stage ${ }^{[24,25]}$. A variety of phenolic compounds have been reported in red mangrove stems, such as ferulic acid, vanillic acid, protocatechuic acid, chlorogenic acid, caffeic acid, benzoic acid, 
gallic acid, ellagic acid, epicatechin and catechin ${ }^{[26,27]}$. On the other hand, it has been reported that red mangrove leaves contain quercetin, epi-catechin, catechin, 4-hydroxybenzoic acid, kaempferol 3-O- $\beta$ glucopyranoside, quercetin 3-O- $\beta$-glucopyranoside, quercetin 3-O-6"-trans-coumaroyl- $\beta$-glucoside, kaempferol 3-O- $\beta$-rutinoside and quercetin 3-O- $\beta$ rutinoside $^{[28]}$. Finally, ethanol extracts of $R$. apiculata roots (a species closely related to $R$. mangle) show the presence of quercetin, gallic acid and rutin ${ }^{[29]}$. It is important to note that the phenolic profile of any plant also varies according to the method and solvent used in the extraction. This means that red mangrove may contain more phenolic compounds than stated here, and bioactivity may vary from one extract to another ${ }^{[10]}$.

Several of the above-mentioned compounds have been tested individually against Fusarium fungi, with good results. In particular, Shukla and Dwivedi ${ }^{[30]}$ reported mycelial growth inhibition of $F$. oxysporum f. sp. ciceri and F. udum (up to $98 \%$ ) when grown in culture medium supplemented with benzoic acid. Furthermore, Ferrochio et al. ${ }^{[31]}$ determined that the antifungal effect of ferulic acid on $F$. verticillioides and $F$. proliferatum depends on its concentration and water activity $\left(\mathrm{a}_{\mathrm{w}}\right)$. Specifically, fungal growth was decreased by $50 \%$ at high ferulic acid concentrations $(20-25 \mathrm{mM})$ and high $\mathrm{a}_{\mathrm{w}}$ (0.99 and 0.98). Fumonisin accumulation on maize-based medium was also reduced by high doses of ferulic acid, even at high $\mathrm{a}_{\mathrm{w}}{ }^{[31]}$.

In this study, differences in the concentration of mangrove extracts required to inhibit fungal isolates was detected. Specifically, a greater concentration of stem extract is necessary to inhibit $F$. verticillioides isolates by $50 \%$, as compared to leaf and root extracts. Although the phenolic composition of the extracts used in this study is unknown, the specific concentration of each phenolic compound depends on the plant organ, which in turn has an effect on the antifungal capacity of each extract. Hussin et al. ${ }^{[6]}$ reported different phenolic profiles and antifungal activities from leaf, stick and bark methanol extracts in Barringtonia racemosa. Leaf extracts displayed the greatest diversity and concentration of phenolic compounds (i.e. gallic acid, naringin, rutin, kaempferol, ferulic acid and luteolin), as well as the highest percent of Fusarium inhibition (53.45\%). Moreover, the differences in phenolic compound and gallic acid concentration were capable of influencing the inhibition percentages of stick $(31.61 \%)$ and bark $(41.38 \%)$ extracts in B. racemosa.
Even when the three $F$. verticillioides isolates were inhibited, isolate DA42 exhibited a greater inhibition over each extract. This observation can be explained by genotypic differences among the isolates. Recent studies from our laboratory on the genetic and pathogenic variability of these and other isolates have determined that each isolate represents a different genotype that can infect maize, although differences in aggressiveness were observed ${ }^{[32,33]}$. Furthermore, different inhibition percentages were recorded between fungal isolates challenged with Bacillus cereus sensu lato strain B25 (unpublished data).

In this study, fungal growth inhibition by phenolic extracts required higher concentrations as compared to benomyl. Indeed, the benomyl dose-response curve indicates that all isolates were $100 \%$ inhibited at $2.5 \mathrm{mg} / \mathrm{ml}$. Similar results were reported by Gale et al. ${ }^{[34]}$ in their inhibition assay against $F$. graminearum. Other studies have reported the inhibition of different Fusarium species with low concentrations of benomyl ${ }^{[35]}$. It is suggested that the control exerted by benomyl may be partially due to its purity, whereas the phenolic extracts are a mixture of several compounds that interact with each other, and which may interfere with the biological activity they exert. This underscores the necessity to analyse the profile of each phenolic extract, to determine the individual phenolic compounds present in them, and to evaluate the antifungal activity of the identified compounds (both individually and combined), which will improve our understanding of how these compounds inhibit fungal growth. This study demonstrates the inhibitory activity of ethanol extracts from $R$. mangle roots, stems and leaves against different isolates of $F$. verticillioides. Furthermore, our data indicate that leaf and root extracts were more effective than stem extracts at inhibiting this pathogen. Additional analyses are needed to determine the phenolic composition of the evaluated extracts, and to identify the phenolic compounds responsible for their antifungal activity. Future research should investigate the effect of these extracts on other pathogenic fungi, as well as the production of mycotoxins produced by the $F$. verticillioides and other fungal species.

\section{Acknowledgements:}

The authors are grateful to the Secretaría de Investigación y Posgrado (SIP) del Instituto Politécnico Nacional (SIP-20120079, SIP-20130398) 
and Fomix CONACYT-Campeche (FOMIXCAMP-2010-144280) for financial support. IGMA acknowledges the Consejo Nacional de Ciencia y Tecnología (CONACyT, México) and SIP-IPN for Ph.D. fellowships. We thank Dr. Brandon Loveall of Improvence for English proofreading of the manuscript.

\section{Conflicts of interest:}

The authors declare that there is no conflict of interests in this paper.

\section{Financial support and sponsorship:}

Nil.

\section{REFERENCES}

1. Zabka M, Pavela R. Antifungal efficacy of some natural phenolic compounds against significant pathogenic and toxinogenic filamentous fungi. Chemosphere 2013;93:1051-6.

2. Kathiresan K, Bingham BL. Biology of mangroves and mangrove ecosystems. Adv Mar Biol 2001;40:81-251.

3. Bandaranayake WM. Bioactivities, bioactive compounds and chemical constituents of mangrove plants. Wetl Ecol Manag 2002;10:421-452.

4. Banerjee D, Chakrabarti S, Hazra AK, Banerjee S, Ray J, Mukherjee B. Antioxidant activity and total phenolics of some mangroves in Sundarbans. Afr J Biotechnol 2008;7:805-10.

5. Suh SS, Hwang J, Park M, Park HS, Lee TK. Phenol content, antioxidant and tyrosinase inhibitory activity of mangrove plants in Micronesia. Asian Pac J Trop Med 2014;7:531-5.

6. Hussin NM, Muse R, Ahmad S, Ramli J, Mahmood M, Sulaiman MR, et al. Antifungal activity of extracts and phenolic compounds from Barringtonia racemosa L. (Lecythidaceae). Afr J Biotechnol 2009;8:2835-42.

7. Afzal M, Mehdi FS, Abbasi FM, Ahmad H, Masood R, Inamullah, et al. Efficacy of Avicennia marina (Forsk.) Vierh. Leaves extracts against some atmospheric fungi. Afr J Biotechnol 2011;10:10790-4.

8. Alizadeh-Behbahani B, Tabatabaei-Yazdi F, Shahidi F, Mohebbi M. Antifungal effect of edible film (CMC) containing aqueous and ethanolic mangrove plant extract on Citrus pathogens in vitro. J Agric Sci 2013;2:47-52.

9. Haq M, Sani W, Hossain ABMS, Taha RM, Monneruzzaman KM. Total phenolic contents, antioxidant and antimicrobial activities of Bruguiera gymnorrhiza. J Med Plants Res 2011;5:4112-8.

10. Kumar VA, Ammani K, Siddhardha B, Sreedhar U, Kumar GA. Differential biological activities of the solvent extracts of Ceriops decandra (Griff.) and their phytochemical investigations. J Pharm Res 2013;7:654-60.

11. Powar PS, Chavan SR, Gaikwad DK. Antifungal activity of mangrove bark. Int J Pharma BioSci 2011;2:484-8.

12. Vadlapudi V, Naidu KC. In vitro bioefficiency of marine mangrove plant activity of Rhizophora conjugata. Int $\mathrm{J}$ Pharmtech Res 2009;1:1598-600.

13. Dambolena JS, López AG, Meriles JM, Rubinstein HR, Zygadlo JA. Inhibitory effect of 10 natural phenolic compounds on Fusarium verticillioides. A structure-propertyactivity relationship study. Food Control 2012;28:163-70.
14. Dambolena JS, Zygadlo JA, Rubinstein HR. Antifumonisin activity of natural phenolic compounds: A structure-propertyactivity relationship study. Int J Food Microbiol 2011;145:140-6.

15. Leslie J F, Summerell BA. The Fusarium laboratory manual. Iowa, USA: Blackwell Publishing; 2006.

16. Munkvold GP. Epidemiology of Fusarium Diseases and their Mycotoxins in Maize Ears. Eur J Plant Pathol 2003;109:705-13.

17. Stumpf R, dos Santos J, Gomes LB, Silva CN, Tessmann DJ, Ferreira FD, et al. Fusarium species and fumonisins associated with maize kernels produced in Rio Grande do Sul State for the 2008/09 and 2009/10 growing seasons. Braz J Microbiol 2013;44:89-95.

18. Pearson TC, Wicklow DT. Detection of Corn Kernels Infected by Fungi. Trans ASABE 2006;49:1235-45.

19. Morales-Rodríguez I, Yañez-Morales M, Silva-Rojas HV, García-de-Los-Santos G, Guzmán-de-Peña DA. Biodiversity of Fusarium species in Mexico associated with ear rot in maize, and their identification using a phylogenetic approach. Mycopathologia 2007;163:31-9.

20. Reyes-Velázquez WP, Figueroa-Gómez RM, Barberis M, Reynoso MM, Rojo FG, Chulze SN, et al. Fusarium sp. (section Liseola) occurrence and natural incidence of beauvericin, fusaproliferin and fumonisins in maize hybrids harvested in Mexico. Mycotox Res 2011;27:187-94.

21. Adom KK, Liu RH. Antioxidant Activity of Grains. J Agric Food Chem 2002;50:6182-7.

22. Madhurima B, Punarbasu C. Antimicrobial potential of leaf extracts of ten mangrove species from Indian Sundarban. Int J Pharm Bio Sci 2014;5:294-304.

23. Ansari MA, Anurag A, Fatima Z, Hameed S. Natural phenolic compounds: A potential antifungal agent. In: Méndez-Vilas A, editors. Microbial pathogens and strategies for combating them. Spain: Formatex Research Center; 2013. p. 1189-95.

24. Kreft S, Štrukelj B, Gaberščik A, Kreft I. Rutin in buckwheat herbs grown at different UV B radiation levels: comparison of two UV spectrophotometric and an HPLC method. J Exp Bot 2002;53:1801-04.

25. Fabjan N, Rode J, Košir IJ, Wang Z, Zhang Z, Kreft I. Tartary buckwheat (Fagopyrum tataricum Gaertn.) as a source of dietary rutin and quercitrin. J Agric Food Chem 2003;51:6452-645.

26. Moran EF, Zamora LA, Stephens NA, Yáñez GA, Virgen $\mathrm{OA}$, Martínez $\mathrm{CO}$, et al. Antioxidant capacity, radical scavenging kinetics and phenolic profile of methanol extracts of wild plants of southern Sonora, Mexico. Trop J Pharm Res 2014;13:1487-93.

27. Sánchez Perera LM, Varcalcel L, Escobar A, Noa M. Polyphenol and phytosterol composition in an antibacterial extract from Rhizophora mangle L. bark. J Herb Pharm 2008;7:107-28.

28. Costa FD, da Silva MD, Borges RM, Leitão GG. Isolation of phenolics from $R$. mangle by combined counter-current chromatography and gel-filtration. Nat Prod Commun 2014;9:1729-31.

29. Asha KK, Mathew S, Lakshmanan PT. Flavonoids and phenolic compounds in two mangrove species and their antioxidant property. Indian J Mar Sci 2012;41:259-64.

30. Shukla A, Dwivedi SK. Antifungal approach of phenolic compounds against Fusarium udum and Fusarium oxysporum f.sp.ciceri. Afr J Agric Res 2013;8:596-600. 
31. Ferrochio L, Cendoya E, Farnochi MC, Massad W, Ramirez ML. Evaluation of ability of ferulic acid to control growth and fumonisin production of Fusarium verticillioides and Fusarium proliferatum on maize based media. Int J Food Microbiol 2013;167:215-20.

32. Leyva-Madrigal KY, Larralde-Corona CP, Apodaca-Sánchez MA, Maldonado-Mendoza IE. Fusarium species from the Fusarium fujikuroi species complex involved in mixed infections of maize in northern Sinaloa, Mexico. J Phytopathol 2014;163(6):486-97.

33. Leyva-Madrigal KY, Sandoval-Castro E, Calderón-Vázquez
CL, Larralde-Corona CP, Maldonado-Mendoza IE. Pathogenic and genetic variability of Fusarium verticillioides from maize in northern Mexico. Can J Plant Pathol 2017;39(4):486-96.

34. Gale LR, Chen LF, Hernick CA, Takamura K, Kistler HC. Population analysis of Fusarium graminearum from wheat fields in Eastern China. Phytopathology 2002;92:1315-22.

35. Mamza WS, Zarafi AB, Alabi O. In vitro evaluation of six fungicides on radial mycelial growth and regrowth of Fusarium pallidoroseum isolated from castor (Ricinus communis) in Samaru, Nigeria. Arch Phytopathol Plant Protect 2008;4:65-71. 